\title{
SOME OBSERVATIONS ON THE DEVELOPMENT OF THE COLOUR SENSE.
}

\author{
BY CHARLES S. MYERS.
}

1. A new Method of Experiment. 2. A Method of Grasp and Reward. 3. Experimental Data. 4. Advantages of Second Method. 5. Legitimate Conclusions from these experiments. 6. Illegitimate Conclusions. 7. Conceptions of the Development of the Colour Sense. 8. The Significance of Observations on the Colour Sense of Primitive Peoples. 9. General Conclusions.

I PROPOSE to give an account of some observations made by me during the years 1905-6 on my elder child. They are less numerous and were, for the most part, made somewhat later in the child's life than those recorded by McDougall in the present number of this Journal. Indeed, were it not for the appearance of his very suggestive paper, I should not have thought it worth while to publish them as they now stand. They are of interest, however, inasmuch as they independently confirm several of McDougall's conclusions, and enable me to describe a method which is in some respects, I venture to think, preferable to the method employed by Marsden and him. Moreover, finding that I differ widely from these and from other observers as to the justifiability of deducing from their data the order of development of colour sensations in infants, I take this opportunity of expressing my views on this subject in particular, and on the development of colour vision in general.

1. I prepared for my experiments a number of wooden cubes ('bricks') each measuring $33 \times 20 \times 15$ millimetres, and I painted each of them uniformly in a different shade of grey or colour. I placed a pair of these bricks before the infant upon a table covered with a piece of black velvet; the table was placed near a window, and the infant sat comfortably before the table on her mother's lap with her 


\section{Observations on the development of the Colour Sense}

back to the window. A black screen was interposed while the bricks were being placed in position so as to hide them momentarily from the infant's view. In all the experiments save a few mentioned on p. 357, the two bricks were placed one to the right, the otber to the left of the infant about 15 centimetres apart. They were placed at such a distance from her that she could easily grasp either of them without effort.

I started these experiments in the hope of being able to employ a method which, so far as I am aware, has not been hitherto applied in observations on infant behaviour. I began by using two coloured bricks, one red, the other blue. Each time the infant picked up one of them, say red, she was rewarded by being given a taste of honey, syrup or sugar. When she picked up the other (blue) brick, no reward was given her. In this way I hoped to build up in the infant a definite association between red and the reward, so that she would always tend to select the red brick when it was offered simultaneously with any other (coloured or colourless) brick. I purposely chose a red brick for the construction for this association, as the natural preference of children for this colour is so well marked.

By this method I hoped to be able to show what colours tended to be confused with red. If, as has been generally supposed, the blue sensation is lacking in early life, it was quite conceivable that the infant would have reacted to a purple or carmine in the same way as she would have done to a red of the same brightness. She would have been insensible to the blue component of these colours and would have regarded them as red.

My first attempts at experiment were made on October 12, 1905 during the twenty-fourth week of the child's life. They were continued on Oct. 14, 16, 17, 27 and 28. Abont twelve pairs of bricks were presented each day. I take the following remarks from my note book :

October 14. She does not appear to look at the bricks as a rule before grasping them. Her arm movements are usually made without looking, they sweep over the bricks, occasionally picking up one. On rare occasions she puts the brick to her mouth.

October 16. The same sweeping arm movements occur, the hand grasping the object on coming into contact with it; the gaze subsequently fixed upon the object grasped which is then moved towards mouth. The infant has no clear notion of the source of the honey, and seems quite unable to connect grasp and reward. 
October 27. Still no trace of association between grasp and reward.

October 28. She no longer makes sweeping movements and begins to look before picking up the brick.

As there was not a trace of the desired association on this date, the experiments were now interrupted. They were begun again at the end of December, 1905 (the thirty-fifth week of the infant's life), and were continued with fair regularity until June 4, 1906. By this time I had abandoned the above method, because I foresaw great difficulty in determining whether the grasping of any brick other than red was due to the confusion of its colour with red or to the attractiveness of that colour arising from its novelty. Now, however, this difficulty does not seem to me insuperable; for, if an infant were really blue-blind, it should, ceteris paribus, more often take up carmine than, say, orange instead of red. I have described the method in the hope that future observers may find it worth while to adopt it and to record their experience. It differs from all other methods with which I am acquainted in that it can claim to be a test for colour confusion. In this respect it has the great advantage of being comparable to the methods commonly used for the detection of colour blindness in adults.

2. Between January 14 and May $3 \mathrm{I}$ investigated the sensibility of my child to differences of brightness, using a pair of grey bricks, one lighter than the other. The lighter brick matched a grey compounded on the colour wheel of $129^{\circ}$ white and $231^{\circ}$ black; in the case of the darkèr brick the proportions werc $50^{\circ}$ white and $310^{\circ}$ black. This pair of grey bricks was presented about ten times at each sitting, sometimes the lighter being on the infant's left, the darker on her right, at other times these positions being reversed. The order of these changes in position was always arranged and written down before the beginning of each sitting. Whenever the infant picked up a brick, she was rewarded with a taste of honey. On January 22 I noted that whenever the brick was taken from her hand, she opened her mouth and projected her chin, clearly showing that she expected the spoon to approach her. On some days subsequently, e.g. on January 31, February 6, 7 and 27, she seemed disinclined to observe the bricks; she showed no signs of expecting the reward, and appeared so little interested and so inattentive that the experiments had to be discontinued. On February 18 my note runs, "very good to-day, certain expectancy of spoon after exhibition of the second pair of bricks," and 
on February 19 "she certainly expected sugar from the first, occasionally dropping the brick of her own accord and at once looking for the sugar." On March 8 she showed disinclination for sugar which was accordingly replaced, with success, by golden syrup.

3. Whenever a brick was picked up, note was taken of its shade and of the hand (right or left) that picked it up. If both hands were put forward, the object recorded as chosen was that which she grasped first. The following results were obtained :

$\begin{array}{cc}\text { Shade of brick } & \text { Number of times selected } \\ \text { Light grey } & 101 \\ \text { Dark grey } & 75\end{array}$

Having thus demonstrated the effect of relatively small differences of brightness on the infant's choice of a brick, I proceeded on May 7, 9, 10, 14 to use a vivid yellow brick and an intensely white brick, presenting them in pairs as before. I obtained the following results :

$\begin{array}{lc}\text { Brick } & \text { Number of times selccted } \\ \text { Yellow } & 27 \\ \text { White } & 8\end{array}$

These figures show very clearly the superior attractiveness of yellow, when presented with white, in spite of the greater brightness of the latter.

On May 15 I began to use a saturated-blue brick and a white one. In eight choices the blue was always picked up, the white never. So far, the results were even more striking than those obtained from the yellow and white bricks. At the next sitting, however, on May 24, the blue brick was chosen only seven times, the white thrice, in ten trials. Continuing with the use of these blue and white bricks on May 29, 30, 31 (twice this day), June 4 and 5, I found that the blue brick was picked up 35 times and the white 4.3 times in a total of 78 trials.

These results are interesting as they show the influence exerted by novelty of colour. In the first two experiments the blue brick was obviously preferred on the score of novelty, whereas subsequently the blue and white bricks were picked up almost equally often.

On the other hand, in the experiments with the yellow and white bricks, the yellow was chosen with increased instead of with diminished frequency at successive sittings. The preference for yellow differs, then, from that for blue, in being independent of the factor of novelty. 
During my earliest experiments made in October 1905, I noticed that the infant unquestionably preferred her left hand to her right, the frequency being in the proportion of about five to one. From January onwards, the use of the right hand began to predominate. This is shown in the course of the three groups of experiments just described. Each number in the following table expresses the percentage frequency, the bracketed numbers express the absolute frequency, with which the object was grasped by one or other or by both hands.

\begin{tabular}{|c|c|c|c|c|}
\hline $\begin{array}{c}\text { Age of Infant } \\
\text { 37th-53rd week }\end{array}$ & $\begin{array}{c}\text { Brick } \\
\left\{\begin{array}{l}\text { Light grey } \\
\text { Dark grey }\end{array}\right.\end{array}$ & $\begin{array}{c}\text { Right hand } \\
44 \cdot 5(45) \\
42 \cdot 6(32)\end{array}$ & $\begin{array}{l}\text { Left hand } \\
13 \quad(13) \\
21 \cdot 3(16)\end{array}$ & $\begin{array}{l}\text { Both hands } \\
42 \cdot 5(43) \\
36\end{array}$ \\
\hline 53rd-54th week & $\left\{\begin{array}{l}\text { Yellow } \\
\text { White }\end{array}\right.$ & $\begin{array}{lr}49 & (13) \\
63 & (5)\end{array}$ & $\begin{array}{ll}44 & (12) \\
25 & (2)\end{array}$ & $\begin{aligned} 7 & (2) \\
12 & (1)\end{aligned}$ \\
\hline 54 th -58 th week & $\left\{\begin{array}{l}\text { Blue } \\
\text { White }\end{array}\right.$ & $\begin{array}{ll}80 & (40) \\
70 & (32)\end{array}$ & $\begin{array}{r}(9) \\
(12)\end{array}$ & (1) \\
\hline
\end{tabular}

This table shows very clearly the increasing predominance of grasps by the right hand. It also shows a reduction in the number of grasps by both hands, - an observation directly opposite to that recorded by McDougall (p. 343). It is of interest to note that on each of the five occasions on which the white brick was grasped by the right hand in preference to yellow, it lay to the right of the yellow brick, and was therefore more readily accessible to the infant's right hand than the yellow.

These results show very clearly the importance of repeatedly interchanging the position of the members of each pair of objects in regard to one another. On May 21 and 22 I escaped from this influence of the spatial error by placing the two bricks in the medial plane, one occupying a position four inches nearer the child than the other. On these two days three bricks were used, the same saturated blue, the white and the previously mentioned dark grey brick, each brick being presented with one of the others equally often. The result of twenty-four trials was as follows: right hand grasps 17 times, left hand grasps 7 times: when the blue and white bricks were presented together, they were picked up equally often $(4$ times): when the blue and grey bricks were presented together, the blue was picked up 5 times, the grey 3 times. That is to say, the same preference for hand and the same indifference for blue were observed as have been already described.

4. The advantage of my second method over that of Marsden and McDougall lies in its perfect freedom from the effects of suggestion. 


\section{Observations on the development of the Colour Sense}

These observers, it will be remembered, allowed two woollen balls to dangle from their hands before the eyes of the infant. In such procedure there is every opportunity for the play of suggestion. The experimenter can hardly avoid expecting and desiring the infant to choose a ball of particular colour, and accordingly he is apt (no doubt quite unconsciously) to dangle that ball with greater vigour. In the hands of a trained observer, the method may be quite free from this objection. But when it is adopted by others who are devoid of scientific training, the dangers of suggestion become very considerable.

My 'method of grasp and reward,' as it may be termed, escapes these dangers. It works perfectly well from the child's ninth month onward. Its applicability to still younger children may appear somewhat questionable. It is true that in my six months old child I was unable to build up an association between a particular colour (red) and the reward of sugar (p. 354). But that does not warrant the conclusion that at this age $I$ could not have got the child to expect a reward each time it picked up any brick. On the contrary, I have not the slightest doubt that this second method, the method of grasp and reward, is arailable for infants below the age of nine months.

Only one coloured brick and a grey (or white) one were exhibited to the infant at any one sitting in my method. This appears to me preferable to using combinations of various colours (and greys) indiscriminately at each sitting, as the disturbing effects of novelty of colour are better controlled. Moreover by using the same two bricks throughout a sitting, I was able to escape the likely drawbacks of McDougall's procedure in which each pair was presented twice in succession, their positions, right or left, being transposed on the second presentation.

5. From the experiments which McDougall and $I$ have here published, I believe that we are justified in concluding (a) that at a very early age (probably long before the sixth month) infants are susceptible to relatively small differences of brightness, $(b)$ that at this age reds and yellows are distinctly preferred to other colours and to colourless objects of far greater brightness, and (c) that novelty may play an important part in determining the infant's choice of colour.

6. Thus far, $I$ am in agreement with McDougall and with several others who have drawn conclusions from their investigation of the behaviour of infants to colour. But I wish to enter a very strong protest against the endeavour to trace, on the basis of these experiments, the course of the development of the colour sense. I am convinced that it is extremely dangerous to formulate any opinion on the actual colour 
experiences of an infant as the result of observing what coloured objects it prefers or rejects, when these objects are presented with other coloured or colourless objects.

It is true that the positive results of such experiments may be significant. When, for example, a child shows a distinct preference for yellow, presented with white, that is a clear indication that yellow has a different effect on him from white. And we are doubtless justified in assuming that this difference is not merely an affective and physiological one, producing greater pleasurable excitement in the infant and determining the choice of the brick which is grasped, but that it is also of sensational significance, that is to say, the visual sensation excited by yellow is different in the infant from that excited by white.

When, on the other hand, we consider the negative results of these experiments, we may be led into drawing conclusions which are demonstrably false. Let us suppose that an infant is presented with successive pairs of objects, each pair consisting of a blue and of an equally bright grey object, and that he is observed to choose the grey as often as he chooses the blue (cf. p. 357). Are we justified in concluding from this observation that the child is colour-blind to blue or that his sensation of blue is in any way different from the bluesensation of an adult? Surely not. All we can say is that blue does not attract the infant as powerfully as certain other colours do, notably reds and yellows. Supposing that this infant showed a preference for the taste of syrup when he had to choose between syrup and lemon juice, and supposing that he showed no preference when he had to choose between lemon juice and beer, who would venture to conclude that the sweet taste was already developed in the infant but that the sour and bitter tastes were not yet differentiated from one another? Yet conclusions on precisely these lines are drawn by those who have in a similar manner investigated the colour preferences of infants. McDougall, for example, remarks of his child L. that the results may "seem to indicate that in $\mathrm{L}$. the blue-sense developed later than that for red, and that in the 21st and 22 nd weeks it was still relatively weak, but that in the 23rd week it had overtaken the sense for red" (p. 347). From such an interpretation I strongly dissent. The behaviour of infants in these experiments teaches us only that certain coloured objects are more attractive than other colours or than the colourless (white, grey and black) series.

7. There are various reasons which to my mind make it improbable 


\section{0 Observations on the development of the Colour Sense}

that the infant becomes sensitive to different colours at different times in his life. Naturally, those who uphold the Young-Helmboltz theory of colour vision are eager to prove that first the infant becomes sensible of red, next of green and finally of blue. They appear, however, to forget that this same theory makes the sensation of white dependent (under ordinary conditions) upon the excitation of all three of these fundamental colour processes, and that if at any period in his life the child were colour-blind to green and blue, all objects, coloured and colourless, could only appear as shades of red. Or, to take a less extreme case, if we suppose that an infant is at a certain stage deficient in sensibility of blue, we can hardly avoid the inference that as in course of time this sensibility becomes greater, his experience of white changes pari passu.

Were it not for the demands of theory, who would suppose that the colour sense arrives at maturity in these stages? Who would suppose that the infant becomes sensitive first to the colour of the longest waves of light and later becomes more and more sensitive to the colour of the shorter waves? Would any one, turning to the sense of hearing, hold that the infant is first conscious of the pitch of low tones and later of the pitch of the highest? It might indeed be urged, on the grounds of the infant's readier response to high tones (and of the pitch of his cry), that the order of development is just the reverse.

Surely it is more likely that vibrations of whatever frequency, so long as they affect the infant's retina and cochlea at all, at first evoke merely sensations of light and sound, and that from this primary experience of light the coloured and colourless series of sensations become gradually and simultaneously differentiated, while from the primary experience of sound tones of various pitch and noises are similarly differentiated from one another. It seems to me most improbable that, in the development of the individual or of the race, sensations of one colour region or of one tone region develop before those of other regions. I look on the process of sensory development as a gradual unfolding, a gradual appearance of diversity among experiences which earlier seemed identical.

We ought, I think, to be on our guard against confusing the psychic experience of the individual with the peripheral sensory apparatus with which he is endowed. Whatever theory of colour vision we hold, to whatever degree the sensory apparatus, on which that theory is based, be developed at a given age, it seems to me that the functional activity of that apparatus may at any moment be prevented from fully 
manifesting itself by a temporary insufficiency of experience. I think it highly probable that the primary physiological basis of colour vision is completely installed before the infant has reached the stage when he can successfully differentiate from one another all the various colour sensations which such an apparatus permits him to receive; just as, in foetal life, he is provided with lungs before he can make use of them. If this be true, then it follows that the gradual differentiation of the colour sensations from one another is a process distinct from the developing constituents of the peripheral cerebro-retinal apparatus.

Those who interpret the developing colour sensations of the infant in the light of the Young-Helmholtz theory, may be said to regard the infant as if he were learning to photograph in colours by the threecolour process. At first he has only the 'red plate' to work with, and at this stage red is the sole colour sensation he receives. Later he acquires the 'green' and finally the 'blue plates.' $\mathrm{He}$ is thus at length able to reproduce the colours of the external world faithfully. I am here endeavouring to show that the infant's earliest vision is with more likelihood comparable to the images projected on to the ground-glass screen of a camera, the lens of which is racked quite out of focus. All then is blurred and confused; there are no distinct outlines and no distinctions of colour. I contend that the growing experience of the infant is comparable to the gradual adjustment of the lens. Little by little, colours begin to be simultaneously differentiated from one another. What was at first a homogeneous light is later seen to consist of differently coloured parts.

8. In favour of the late acquisition of the sensation of blue, it is often urged that "the power of appreciating blue colour or the blue sensation was relatively weak in the Homeric Greeks and is so in many peoples of the lower cultures at the present time." This view, which McDougall appears to quote (p. 346) with approval, rests mainly on the absence of a specific word for blue from the vocabularies of these peoples. But language affords no safe clue to sensibility. A colour name occurs when it is needful. Where it is needless, it will not be formed, be the sensibility to that colour ever so great. If we are to gauge the colour sense of a people by colour nomenclature, nearly every primitive people must be dubbed 'brown-blind' or 'brown-weak,' inasmuch as it is very rare to find a special word for brown. Even when the vocabulary of a primitive people contains a separate word for blue (distinct from the word for black), that word is frequently used for green as well as for blue. Indeed blue, green and yellow may share 


\section{Observations on the development of the Colour Sense}

a common colour name. It does not follow, however, that such peoples confuse blue and green or that they cannot distinguish blue from green and yellow.

I do not believe that this absence of a definite word for blue among the Homeric Greeks and modern primitive peoples is necessarily connected with Rivers's observation that the threshold of discrimination between white and the palest blues is higher among coloured races than among Europeans. This difference is probably related to racial differences of pigmentation of the macula lutea, as Rivers has himself suggested ${ }^{1}$. It has only been found among coloured peoples and consequently we have no right to suspect its presence among the ancient Greeks and primitive peoples of the west, who also possessed no distinct colour name for blue.

9. I conclude, then, that we have not sufficient evidence to show that the colour sense materially differs in different peoples, or that the various colour sensations of an infant develop at different periods in his life. The 'red-blindness,' which occurs among the colour-blind, and in the intermediate zone of the normal retina, is strong evidence against the view that red is the first colour-sensation phylogenetically acquired. The one prominent fact, which stands out clearly in this discussion, is that both primitive peoples and infants are attracted most by red and next by yellow; this fact being manifest among the former in their colour nomenclature and among the latter by their readiness to grasp objects of these colours. I suggest that this superior attractiveness of red is a fundamental characteristic far too deeply and immutably ingrained to be attributable, as McDougall so ingeniously suggests, to the greater utility or rareness of red and yellow objects or to the relative unattractiveness of the broad surrounding expanse of uniformly blue sky, blue-green sea and green foliage. The excitatory action of red is manifested in organisms lower than man.

1 Reports of the Cambridge Anthropological Expedition to Torres Straits, Cambridge, 1901, vol. II. pp. 79,80 . 